\title{
Overview of migration, poverty and health dynamics in Nairobi City's slum settlements
}

\author{
Eliya M. Zulu, Donatien Beguy, Alex C. Ezeh, Philippe Bocquier,
} Nyovani J. Madise, John Cleland, and Jane Falkingham

\begin{abstract}
The Urbanization, Poverty, and Health Dynamics research program was designed to generate and provide the evidence base that would help governments, development partners, and other stakeholders understand how the urban slum context affects health outcomes in order to stimulate policy and action for uplifting the wellbeing of slum residents. The program was nested into the Nairobi Urban Health and Demographic Surveillance System, a uniquely rich longitudinal research platform, set up in Korogocho and Viwandani slum settlements in Nairobi city, Kenya. Findings provide rich insights on the context in which slum dwellers live and how poverty and migration status interacts with health issues over the life course. Contrary to popular opinions and beliefs that see slums as homogenous residential entities, the findings paint a picture of a highly dynamic and heterogeneous setting. While slum populations are highly mobile, about half of the population comprises relatively well doing long-term dwellers who have lived in slum settlements for over 10 years. The poor health outcomes that slum residents exhibit at all stages of the life course are rooted in three key characteristics of slum settlements: poor environmental conditions and infrastructure; limited access to services due to lack of income to pay for treatment and preventive services; and reliance on poor quality and mostly informal and unregulated health services that are not well suited to meeting the unique realities and health needs of slum dwellers. Consequently, policies and programs aimed at improving the wellbeing of slum dwellers should address comprehensively the underlying structural, economic, behavioral, and service-oriented barriers to good health and productive lives among slum residents.
\end{abstract}

KEYWORDS Urbanisation, poverty, health dynamics, Urban slum, Korogocho, Viwandani, Nairobi, Kenya

\section{INTRODUCTION AND BACKGROUND}

High rates of urban growth that have unfolded in the context of stagnating economies and poor planning and governance have created a new face of abject poverty concentrated in informal settlements, commonly referred to as slum settlements or slums, in Africa's major cities. Recent estimates by UN-Habitat show that sub-Saharan Africa (SSA) is the only region where no tangible progress has been made in improving the lives of slum dwellers in line with the targets set under the

Zulu is with the African Institute for Development Policy (AFIDEP), Nairobi, Kenya; Beguy and Ezeh are with the African Population and Health Research Center (APHRC), Nairobi, Kenya; Bocquier is with the Université Catholique de Louvain, Louvain-la-Neuve, Belgium; Madise and Falkingham are with the University of Southampton, Southampton, UK; Cleland is with the London School of Hygiene and Tropical Medicine, London, UK.

Correspondence: Eliya M. Zulu, African Institute for Development Policy (AFIDEP), Nairobi, Kenya. (E-mail: eliya.zulu@afidep.org) 
Millennium Development Goals (MDGs) framework. While the proportion of urban residents living in slum settlements has declined from $70 \%$ to $62 \%$ between 1990 and 2010, the actual number of slum dwellers has doubled from 103 million to 200 million over this period. ${ }^{1}$ Slum settlements are characterized by poor housing conditions, poor social services, poor basic amenities, poor health outcomes, insecurity, and unstable incomes and livelihoods. If these patterns and trends continue unchecked, the region's socioeconomic prospects will increasingly be determined by the lives of the urban poor since urban areas will continue to grow faster than rural areas in SSA. ${ }^{2}$

The rapid increase in urban population has been mostly driven by high natural increase, which accounts for about $75 \%$ of the urban growth in Africa, compared to about $50 \%$ in Asia. ${ }^{3}$ This high natural increase is due to the relatively high level of fertility, which remains far above replacement level in most countries. Furthermore, the relatively high proportions of people of reproductive age in urban populations results in a high number of births. Although the contribution of migration to urban growth is low in Africa compared to other developing regions, the highly circular nature of ruralurban migration in the continent ${ }^{4}$ means that there is quite heavy back-and-forth mobility of young adults who escape the worsening rural economic conditions and join the unpredictable urban setting in search of better livelihood opportunities.

Kenya typifies Africa's escalating urban crisis, with projections that about $55 \%$ of its urban population lives in slum settlements and that this number has not changed between 1990 and 2009. ${ }^{1}$ Nairobi, Kenya's capital city and national economic hub, has seen its population grow from 120,000 in 1948 to 3,138,369 in 2009. The annual growth rate was about 5\% between 1989 and 1999, and 4\% during the 1999-2009 decade despite the fall in employment opportunities associated with the economic downturn in Kenya from the 1980s. ${ }^{6}$ UN-Habitat estimates indicated that between 60 and $70 \%$ of the Nairobi city dwellers live in slum settlements. ${ }^{7,8}$

Studies in the slum settlements of Nairobi and in other settings in SSA have highlighted the significant disadvantages faced by the urban poor with respect to morbidity, ${ }^{9,10}$ access to health services, ${ }^{9-15}$ mortality, ${ }^{16-18}$ and risky sexual practices $^{19-21}$ relative to other population sub-groups, including rural residents. ${ }^{22}$ Studies in other settings have also come up with broadly similar findings. ${ }^{23-28}$ Although these studies have documented the magnitude of health inequities between the urban poor and other groups, the dynamic inter-linkages among migration, urban poverty, and health are not fully understood largely because of lack of appropriate data. Additionally, these studies have treated the poverty-health relationship as unidirectional, primarily focusing on poverty's influence on health, thereby overlooking the reverse direction of this relationship, i.e., effects of ill-health on impoverishment. Given the poor living conditions and livelihood opportunities that are observed in most metropolitan centers in the region, ${ }^{29,30}$ it appears paradoxical that many rural residents continue to flock to urban areas, where most end up in slum settlements. This paradox underscores the need for a better understanding of the drivers and consequences of rural-urban migration.

The global efforts to reduce poverty in developing countries underscore the need for appropriate tools for conceptualizing, measuring, and monitoring poverty. Most measures of poverty have been developed using national or broadly disaggregated spatial categories such as rural versus urban areas. ${ }^{31-33}$ Given the substantial differences between urban and rural poverty on the one hand, and between the urban poor and other urban residents on the other, it is imperative to assess the appropriateness of various measures of economic vulnerability in the slum settlements. ${ }^{34}$ 
It is against the background of the growing importance of urban poverty in shaping urban and national health and socioeconomic indicators, and the knowledge gaps noted above that the African Population and Health Research Center (APHRC), in partnership with the London School of Hygiene and Tropical Medicine (UK), the University of Southampton (UK), and the Institut de Recherche pour le Développement (France), designed and implemented the Urbanization, Poverty, and Health Dynamics (UPHD) Research Program between 2006 and 2010, with funding from the Wellcome Trust. The program's overarching research aim was to examine the dynamic inter-linkages between migration, poverty, and ill-health in the slum setting. Additionally, the program sought to investigate whether these linkages vary at different stages of the life course namely, childhood, adolescence, adulthood, and old age. In particular, the study sought to investigate whether the people who move to slum areas are responding to life crises that have had deleterious impacts on their health or whether it is slum residence itself that has adverse consequences on the health and well-being of the residents. The program validated the relevance of various measures of poverty in informal urban settlements and sought to identify the most appropriate indices for understanding the inter-linkages between poverty and health outcomes over time and across the life course.

\section{STUDY DESIGN}

The UPHD research program represented the first effort to address the linkages between urbanization, poverty, and health dynamics using a longitudinal framework located in an urban poor setting in sub-Saharan Africa. The examination of these issues at different stages of the life course further provided an opportunity for a holistic understanding of these linkages. As the number of people living in slum settlements increases, policymakers need to understand how urban poverty affects and is itself affected by health at different stages of the life course so that effective interventions for the urban poor can be designed and implemented.

The UPHD was nested into the Nairobi Urban Health and Demographic Surveillance System (NUHDSS), the first urban-based demographic surveillance system in Africa. APHRC has been implementing the NUHDSS in two of the numerous informal settlements in Nairobi city-Korogocho and Viwandani-since August 2002. The NUHDSS involves visits to all households once every 4 months to collect information on key demographic and health events, including births, migrations, deaths, and causes of death (through verbal autopsies). Other events being monitored (though not necessarily in every visitation round) include immunization coverage, morbidity, health-seeking behavior, school attendance, marital status, household possessions and amenities, and livelihood sources. In addition, a series of nested panel surveys are designed to investigate detailed information on underlying determinants of the health, education, and demographic outcomes that are collected routinely in the NUHDSS. Between 2003 and 2007, the NUHDSS was monitoring an average of about 70,000 individuals living in about 28,000 households in the two settlements.

The UPHD adopted the life course approach in order to assess how migration, urban poverty and health status influence each other at different stages of the life cycle. Figure 1 shows the conceptual framework that guided the issues that the study investigated and the nature of data that we collected and analyzed. We examined the 


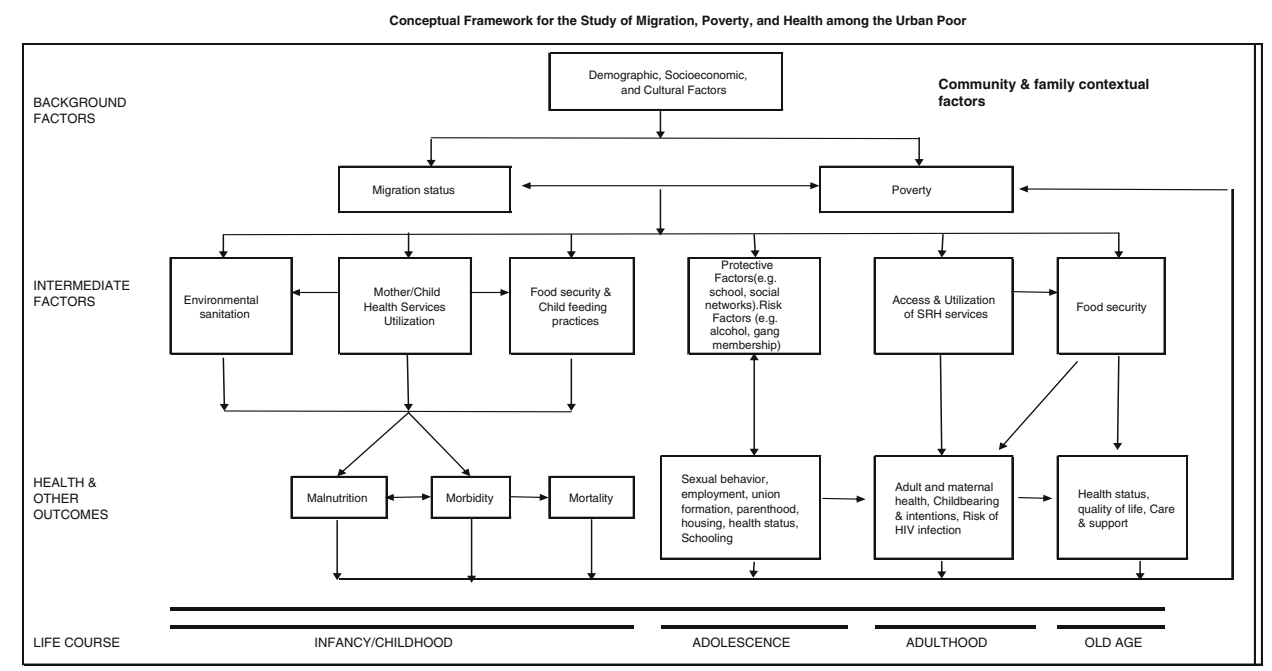

FIGURE 1. Conceptual framework for the study of migration, poverty, and health among the urban poor.

key background and intermediate factors that affect the key health outcomes at the four stages of the life course. The intermediate factors represent mechanisms through which migration and poverty is likely to affect health outcomes and vice versa.

The UPHD employed a combination of quantitative and qualitative methodologies to address its research questions. Quantitative methods were used to analyze the routinely collected longitudinal data under the NUHDSS as well as new data collected through nested surveys that were designed to provide explanatory variables underlying six thematic areas: migration, poverty, child health, adolescent transition to adulthood, maternal health, and aging. For each of the thematic areas, at least two nested studies were carried out in order to determine drivers of change in the outcome variables over time. A random super sample of close to 8,200 households from the two NUHDSS sites 15,200 in Viwandani and 3,000 in Korogocho) was first drawn for the new surveys, yielding about 6400 and 9000 people aged at least 12 years in Korogocho and Viwandani, respectively. All the people aged 12 and above in the super sample were interviewed for the migration component. Samples for adolescent transition to adulthood and poverty were sub-samples of the super sample. For the aging component, all elderly people and their households were interviewed. For the child and maternal health themes, however, updates were done every 4 months in order to monitor short-term changes in child growth, nutritional status, and various postpartum outcomes for mothers who gave birth since September 2006 while residing in the NUHDSS surveillance area.

The program conducted a series of qualitative studies through in-depth interviews and focus group discussions to help design quantitative questionnaires and to gain further insight on various behavioral patterns observed in the survey results. The qualitative data were collected on the following issues: understanding of poverty; reasons for migration, satisfaction with migration decisions, and future migration intentions; challenges faced by young people, their career aspirations, and the efforts being made to achieve those aspirations; and consequences of migration to urban poor settlements on health and general well-being of elderly people. 
The UPHD's primary outputs were scientific publications in peer-reviewed journals. A total of 52 articles have been published by the team using existing and new data collected under the program, including the current special issue of the Journal of Urban Health, and many others are under review. The program has generated significant evidence that has informed various advocacy, policy, and interventions in Kenya and across SSA. Seven junior researchers who were not part of the UPHD research team were awarded research internships at APHRC, where they used UPHD data to conduct analyses for their Masters or PhD theses. Between 2006 and 2010, ten postdoctoral fellows as well as four $\mathrm{PhD}$ and two Masters students were involved in the various UPHD sub-themes. Nine training workshops on data analysis were organized for UPHD researchers, either at APHRC or at partner institutions.

\section{ABOUT THIS VOLUME}

In order to broaden dissemination of findings from the UPHD research program and promote scientific and policy discourse on urban poverty and health issues in SSA, the investigators of the UPHD program and the management of the Journal of Urban Health agreed to publish a collection of new papers from the program in a special issue of the journal. This volume presents the first journal collection of papers examining urban health and poverty dynamics based on such comprehensive data collected in slum settlements. The papers describe the study context and help to enhance understanding of how this context affects the key health challenges experienced by the urban poor. The structure of the volume is organized around five themes. The first theme covers the crosscutting topics of poverty and migration patterns and dynamics. The four other themes are organized following the lifecycle approach of the study, with papers addressing various issues related to childhood, adolescence, adulthood (maternal health), and old age.

\section{Context: Fertility, Mortality, Migration, and Poverty}

The first theme on the context of urban poverty contains four papers on key demographic and health indicators of the study communities, as well as on migration patterns and poverty-related conditions.

The NUHDSS chapter by Emina et al. describes the NUHDSS framework and assesses trends in the key health and demographic outcomes derived from longitudinal data collected over the period 2003-2009. The findings show that the overall population did not change much over the 7 years that the surveillance has been in place $(16.3 \%$ increase), but there is considerable in-and-out mobility of the population. The paper shows that fertility has not changed much, but child mortality rates have gone down quite substantially in both slum settlements. These trends are in line with improvements in socioeconomic status and reduction in poverty as shown in this paper. Compared to other sub-populations in Kenya, slum settlements exhibit higher mortality than Nairobi as a whole, other urban areas, as well as rural areas. The migration findings show that the majority of the slum residents were not born in Nairobi city, and they migrated from rural areas in search of livelihood opportunities. While the slum population is highly mobile, there is a sizable proportion of people who have lived in slums for long periods of time (more than 10 years). Most of those who live in the slums rely on casual jobs as their main source of income. Furthermore, while the poverty head count declined from $55.4 \%$ to $34.7 \%$ between 2006 and 2009, the uniqueness of the NUHDSS allows us to observe that about $30 \%$ of those who were above the poverty line went below the 
poverty line, whereas $47 \%$ of those who were below the poverty line went above the poverty line over the period.

Using qualitative data, the second paper by Mudege and Zulu discusses the migrants' extent of satisfaction with their decision to migrate to the slum settlements and their future migration intentions. The paper demonstrates that the limited economic opportunities in rural areas push people to migrate to Nairobi, where they endure the poor living conditions in slum settlements because these are the only places in the city where migrants can afford rent and save some money for investment in their rural homes. Many of the respondents felt like they are trapped in the slum settlements because of lack of viable alternatives. However, the paper also notes that people who have been relatively successful economically and who own fixed property, such as housing, are likely to live in the slums for a long time in order to protect their property and acquire more. The people who were satisfied with their migration decisions often referred to their ability to pay fees for their children back home. The poor environmental conditions in the slum settlements were frequently mentioned as a source of dissatisfaction. Many slum residents were prepared to endure the poor environmental and livelihood conditions because, unlike in rural areas, a hardworking person could still find something to do and make some money in the city. Whether people intend to move out of the slum settlements or not depended largely on their perceived chances of succeeding economically and the nature of economic prospects in their rural homes and other possible destinations.

The third paper by Faye et al. assesses the scope of food insecurity and hunger among households in the two slum settlements, drawing evidence from the household possessions and livelihood data collected under the NUHDSS. The paper provides prevalence estimates and determinants of food insecurity and hunger for households in the two settings. The paper found that food insecurity is pervasive among slum dwellers in Nairobi, with only about $20 \%$ of households being classified as food secure and close to $50 \%$ of households as "food insecure with both adult and child hunger." Households that are more likely to be food insecure are those with low incomes, that are female headed, and/or that are headed by someone with no education or who is a recent migrant. Household composition also matters, with households containing both children under 11 years old and adults aged 50 years and older exhibiting relatively high levels of food insecurity. This study demonstrates the validity of the NUHDSS data collection instrument that could be used to continuously monitor food insecurity and hunger in Nairobi slums and beyond.

Building on an earlier paper written by the UPHD investigators, which documented the burden of disease among slum dwellers, ${ }^{35}$ the fourth paper by Ziraba et al. investigates causes of and risk factors for fatal injuries, using verbal autopsy data from the NUHDSS. The paper found that injuries contributed significantly to the high level of morbidity and mortality attributable to non-communicable diseases in slum settlements. About half $(51 \%)$ of the injuries were intentional, with homicides accounting for $91 \%$ of intentional injuries. Deaths due to injuries are mainly caused by firearm injuries $(23 \%)$ and road traffic accidents (22\%). Substance intoxication subsequent to consumption of illicit alcohol in these communities is the cause of $15 \%$ of injuries. Factors significantly associated with the risk of fatal injuries include ethnicity, slum location, and communitylevel factors such as the level of poverty and the proportion of single-person households.

\section{Well-being of Children}

The second theme includes two papers that look at the well-being indicators during childhood, including mortality and food security. 
The first paper by Bocquier et al. uses event history analysis to examine the impact of mother and child migration on the survival of about 10,445 children under five years of age in the Korogocho and Viwandani informal settlements between 2003 and 2007. The paper found that children born in the slum settlements have higher mortality than those born outside slums, suggesting that delivery while residing in slum settlements has debilitating health consequences on children. The highest mortality rate was observed among slum-born children whose mothers were pregnant at the time of migration. Findings from this study suggest that there is need to address health inequities even within the so-called "marginalized groups." In particular, targeted health policies toward children of recent migrants who are exposed to high health hazards in the slums could be developed in the light of the high degree of circular migration in these communities (as shown by the UPHD team in another paper by Beguy et al.). ${ }^{4}$

The second paper by Kimani et al. sought to explore the relative vulnerability with regards to food security and nutritional outcomes of vulnerable children and orphans living in the two slum settlements, and to explore the determinants of this vulnerability. The authors examined both nutritional status and food security so as to ascertain the current situation as well as possible long-term effects of orphanhood. Findings indicate that orphans were more vulnerable to food insecurity, with paternal orphans being the most vulnerable among orphans. The results also show that vulnerability was greatest for boys, and children living in households of the lowest socioeconomic status, those that have many dependents, or those that were femaleheaded or headed by adults with low education. These findings could be used to identify target groups and develop intervention programs to improve the living conditions of orphans and vulnerable children living in urban poor communities.

\section{Transition to Adulthood: The Adolescent Years}

Two papers addressed issues related to adolescents living in the two slum areas. In the first paper by Ndugwa et al., the authors examined the applicability and appropriateness of the problem behavior theory and explored the role of psychosocial protective and risk factors in explaining deviant behavior among adolescents aged 12-19. Deviant behavior was defined using a composite index based on delinquent behaviors including: early sexual experience, illicit drug use, alcohol consumption, and tobacco smoking experience. Analyses were done separately for the younger (12-14) and the older (15-19) cohorts. Findings show that for both age cohorts, protective factors were negatively associated with deviant behavior as expected, although non-significant for individual controls protection among the younger adolescents, and for social controls protection among the older adolescents. In addition, in both age cohorts, the two risk factors had a positive association with deviant behavior, with the association being much stronger for the models risk measure. Further analysis indicated the moderating effect of protective factors on the association between risk measures and problem behavior among adolescents. Overall, the study showed that the psychosocial measures as constructed in the problem behavior theory can significantly account for the variation in problem behavior among adolescents in such poor settings in SSA. Policies and programs aimed at improving the health and well-being of adolescents living in urban poor environment could focus on enhancing protective factors, as well as buffering or moderating risk factors identified in this study.

The second paper by Beguy et al. used event history analysis to analyze data from the baseline survey of the UPHD adolescent transition component and investigate the timing and sequencing of four key markers of the transition to adulthood, namely first sex, marriage, birth, and independent housing, among 3,944 
adolescents in the two informal settlements. The authors found that there is no significant gender difference with regard to sexual debut among adolescents. However, the early sexual debut observed for a significant proportion of the adolescents suggests that intervention programs in the slums may need to target adolescents in their early ages in order to significantly reduce their poor sexual outcomes. For most boys and girls, the first sexual experience occurs outside marital unions. For males, the sequencing of transition events begins with entry into first sex, followed by independent housing. However, the sequencing for females begins with first sex and then parenthood. Apart from sexual debut, the patterns of entry into union and parenthood do not differ much from what was observed for Nairobi as a whole. ${ }^{36}$ Findings showed that some females get their first births while they are still young, with high health hazards for the mother and the newborn. Programs should target these young mothers living in the poor slum settings where lack of basic health services and high health care costs impede access to obstetric services. A significant proportion of adolescents leave parental homes at young ages, with boys being more likely to do so than girls. However, in the slum context, leaving home at early ages increases their exposure to risky and delinquent behaviors, such as early sexual intercourse, multiple sexual partnerships, substance and alcohol use.

\section{Reproductive and Maternal Health Challenges During Adulthood}

Two papers in the volume address maternal health issues in the slum settlements of Nairobi. The first paper by Essendi et al. uses qualitative data to investigate men's and women's views on the individual, community, and health facility factors that hinder the uptake of formal obstetric care services in the two slum settlements where maternal mortality ratios are higher than the national average. For every 100,000 live births, 700 women die from pregnancy-related causes in the two slums. ${ }^{37}$ Understanding lay perspectives regarding obstetric care services is paramount in developing programs and policies that will respond effectively to the sensitivities and needs of their expected beneficiaries. The study found that while slum dwellers prefer formal to informal obstetric services, they face various barriers in utilizing formal services. These barriers include ineffective health decision making, inadequate transport services, insecurity, high cost of health services, unfriendly attitudes of health service personnel, and ill-equipped health facilities in the slum settlements. As a result, women often face many health hazards which sometimes culminate in death. To tackle these barriers, the study suggest that women should be educated on pregnancy complications and the need for timely referral. Health workers should receive training in good provider-patient relationship. Improving security at night is also another important way of improving access to appropriate health care in the slums. Finally, given their importance in the delivery services in the slums, TBAs could be involved in referral processes and their skills could also be enhanced.

The second paper by Ndugwa et al. examines the extent and nature of postpartum protection against pregnancy afforded by postpartum amenorrhea, sexual abstinence, and contraceptive use using monthly calendar data. Given the estimates that contraceptive use accounts for one in ten reductions in child mortality and a reduction in maternal mortality of $32 \%,{ }^{38}$ use of modern contraception is very critical for attainment of the MDGs on maternal and child health. The study found that no contraceptive method was used during $28 \%$ of all postpartum months 
where the risk of another pregnancy was high for women. The study shows that postpartum contraceptive use is triggered by menstrual resumption. Women did not exhibit significant differences in their choice of contraceptive methods before and after resumption of menses. Given that a significant proportion of postpartum women living in the two slums are at high risk of unintended pregnancy due to an unmet need for contraception, it may be necessary to move toward integrating family planning services and postpartum care to reach these women. Furthermore, it is recommended that TBAs be trained on postpartum contraception, as their services are often used during delivery by women living in the slum settlements.

\section{Aging in Informal Settlements: Perception and Socioeconomic Context}

The volume contains two papers addressing the well-being of the elderly living in slum settlements in Nairobi. In the first paper by Kodzi et al., the authors examined the effects of religious affiliation, participation, and forms of social engagement (including social support, sociability, and community participation) on the selfreported health status of the elderly aged 50 years and above. In such poor environments generally characterized by poor health outcomes and high religious involvement, it is important to investigate the effects of religion and social engagement on health. The study found that frequency of religious attendance was negatively associated with health. Although counterintuitive, the latter finding suggests that religion may be used to buffer the stress of poor health. The study further found that strong social networks and support mechanisms enhance health status. For instance, positive and independent association was observed between the number of close friends, social support, and frequency of community participation and self-rated health. These findings call for the promotion of community participation in social policies as a way of enhancing health outcomes among the older people living in slum settlements.

The second aging paper by Falkingham et al. assesses functionality and disability among the elderly living in the slum settlements using self-reported health measures. The study investigates whether there are socioeconomic differences in reporting disability among older people in slum settlements. All the indicators showed the expected negative association with health across some of the disability domains. Unlike in many other studies, no significant differences based on occupation were observed. Gender differences were found, with primary education level being a significant factor for women but not for men. On the other hand, wealth index was significantly associated with lower reported disability for men but not for women. Relying on his/her own livelihood was also associated with lower reported disability. By stressing the health inequities in such poor settings that are seemingly homogeneous, these findings call for the need to appropriately identify socioeconomic classification for better measurement and explanation of ill health among older people living in slum settlements.

\section{KEY LESSONS AND IMPLICATIONS OF THE UPHD FINDINGS}

The findings from the collection of papers in this volume and others from the UPHD program make a significant contribution to our understanding of the context in which slum residents live and the linkages among migration, poverty, and health outcomes during childhood, adolescence, adulthood, and old age. The findings also 
provide important pointers on the nature of policies that governments and development partners can explore to uplift the well-being of the urban poor. Finally, there are areas where further research is needed in order to conclusively answer the core research questions that the UPHD was designed to answer.

\section{Who are the Slum Dwellers and How Long Do They Stay?}

One of the key questions about slum settlements relates to who are the people who live in these communities, where they come from, and how long they stay in these communities. The findings presented in this issue and other publications by the UPHD team show that the majority of slum dwellers are not born in Nairobi city, and they come from rural areas to explore the city's livelihood opportunities during their early adult years. Slum settlements are characterized by very high population mobility as demonstrated by the fact that almost $22 \%$ of the people who are members of the NUHDSS at the beginning of the year cease to be members of the system by the end of the year. The high levels of mobility and their determinants have been well documented by Beguy et al. ${ }^{4}$ Amidst this high level of population mobility, however, is a sizable proportion of people who are long-term residents. In fact, a cross-sectional study of randomly selected households carried out in 2006 revealed that close to half of the population at that time had lived in the slums for over 10 years. ${ }^{39}$ While the high levels of migration may raise questions about the suitability of slum settlements for longitudinal studies, the existence of such a sizable proportion of residents that live in slum settlements for this long shows that long-term longitudinal studies and carefully targeted long-term intervention programs can be implemented and evaluated in these settings. The unique vulnerability of recent migrants suggests that specific intervention programs need to be targeted to the highly mobile slum population that may be subjected to specific risks and conditions.

\section{How Homogeneous are Slum Dwellers?}

Another key question regarding slum settlements is the extent of heterogeneity in measures of well-being and health outcomes across and within settlements. The big variations between Korogocho and Viwandani in the composition of their populations, extent of population mobility, livelihood opportunities, nutritional status, food security, and health outcomes demonstrate the danger in taking slum settlements as homogeneous residential entities whose challenges can be addressed through uniform intervention strategies. Variations across households and residential areas within the same slum community are also quite huge. According to analysis that the UPHD Poverty team contributed to the 2008 World Bank poverty and inequality assessment report, slum settlements have high poverty levels as well as inequalities, with female-headed households falling farthest from the poverty line. ${ }^{40}$ Poverty incidence across Korogocho's seven villages varied from $42 \%$ to $78 \%$, while in Viwandani, it varied from $52 \%$ to $66 \%$. The wealthiest decile in either of the two slums had expenditures (per adult equivalent) 14 times higher than the bottom, and the Gini coefficient in 2006 was $0.39 .^{40}$ These huge inequalities extend to health outcomes as shown by the Bocquier et al. paper in this volume, which demonstrates that vulnerabilities to child mortality are far worse among new migrants and those with relatively low socioeconomic status than among long-term residents and those who can afford reasonable amenities. Further research needs to develop methodologies to guide intervention programs to effectively target the worse-off members of slum communities.

The papers that examined health status and access to health care bring out three critical issues. First, poor environmental conditions, poor housing conditions, poor 
security, and poor transportation and walkways exacerbate the vulnerability of residents to infectious diseases and injuries. Second, access to health care is heavily limited by lack of financial resources and, in some cases, by lack of information on how to access health services or lack of proper transportation infrastructure to enable patients to reach health facilities, as is the case for pregnant women who need to reach maternity services at night. Third, the studies highlight how the lives of even those who spare their limited income to pay for the costly health services are endangered by the dominance of the poor quality and mostly informal health services that are not responsive to the unique needs and health challenges of slum residents.

\section{How Do Slum Conditions Affect Health Outcomes at Different Stages of the Life Course?}

These key features of slum settings have profound and varying impacts on the health status and outcomes for slum residents at the different stages of the life course. Slum children bear the biggest burden of the poor environmental sanitation and housing conditions and the poor quality health services. Verbal autopsy data from the NUHDSS has shown that diarrhea and pneumonia are the leading causes of death among children under 5 years old and that the mortality burden among these children is four times higher than in the rest of the population. ${ }^{35}$ These mortality levels are not surprising given that children in the slums have exceptionally low levels of vaccination $(44 \%$ are fully immunized), ${ }^{41}$ exceptionally high levels of malnutrition, and high prevalence of infectious diseases in the midst of poor access to curative health care. ${ }^{42}$ Clearly, in order to improve child health outcomes in slum settlements, there is a need for a policy and program shift to ensure massive improvement of the poor environmental sanitation conditions and quality of primary health care services.

Young people growing up in slum settlements face serious challenges as they transition from childhood to adolescence and to the key markers of adulthood, including employment, parenthood, and independent housing. The transitions from childhood to adolescence are mostly dominated by challenges related to poor schools, poor educational outcomes, sexual maturation, relatively early indulgence in sex, and risky sexual practices such as unprotected sex and multiple sexual partnerships. Analyses by the UPHD team members have shown that girls who grew up in the slums are the most vulnerable to risky sexual behaviors. ${ }^{19,20}$ Just as poor quality health services aggravate mortality risks for slum children, reliance on informal primary schools also exposes slum children to one of the lowest secondary school progression rates in the country. A significant proportion of female adolescents become mothers at very young ages, with $34 \%$ of those aged 18-19 having had a child. The lack of jobs and other stable livelihood opportunities also affects young people living in slum settlements disproportionately, as shown in the Kenya World Bank report. The analysis in this volume by Ndugwa et al. underscores the need to identify and address the risky factors and reinforce the protective ones in order to improve schooling, economic, sexual, and reproductive health outcomes of young people in slum settlements. Provision for good and supportive school environments, constructive leisure activities, relevant sexual and reproductive health information and services, and opportunities for enhancement of economic skills would go a long way in protecting and developing slum children into healthy and productive citizens in future.

The key health challenges facing women in slum settlements include high vulnerability to HIV infection, ${ }^{37}$ high maternal mortality rates and low utilization of 
life-saving safe motherhood services such as obstetric care, ${ }^{12,14,43}$ and high unmet need for family planning (Ndugwa et al., in this volume). The low levels of income and low quality of maternity services, including substantial reliance on traditional birth attendants, are key contributing factors to the high maternal mortality rates in slums. The evidence generated by the UPHD team on maternal health issues is vital to guiding policies and program interventions to improve maternal health outcomes in slum settlements. For example, the Government of Kenya and its partners piloted the output-based aid voucher scheme to fund safe deliveries, family planning services, and gender-based violence recovery services in Korogocho and Viwandani communities. If the results are positive, there are plans to explore how such a program can be scaled up to other areas. The UPHD results also contributed to the evidence base for the Bill \& Melinda Gates Foundation's new Urban Reproductive Health Initiative being implemented in Kenya, Nigeria, Senegal, and India. The initiative seeks to develop, test, and evaluate interventions aimed at increasing contraceptive prevalence by $20 \%$, especially among the urban poor.

The UPHD's research on the well-being of the elderly living in slum settlements has highlighted fundamental social and health challenges facing older people living in these settings. Many of the elderly living in these settings have lived there for many years, having relocated to the slums during their 20s or 30s. Many of them have no plans or ability to leave slum settlements. ${ }^{44}$ Since the Nairobi city economy is cash-based, many of the elderly have to continue working beyond their retirement age, and in the growing presence of ill-health, in order to make a living and cater for their lack of pension or social support systems.

The growing number of the elderly living in these settlements calls for integration of the needs of older people in city planning and service provision. The health care system that serves these communities needs to accommodate the fact that the high disease burden due to communicable diseases in slum settlements is compounded by the increasing vulnerability to non-communicable diseases among the elderly. Findings of a cardiovascular diseases study that developed from the UPHD found that about $12 \%$ of adults aged 18 years and above living in the two slum communities are hypertensive, with the prevalence increasing with age $(10 \%$ among those aged 30-39 years as compared to $43 \%$ among those aged 60 years and above). About $4 \%$ of adults had diabetes, with those aged between 40 and 60 years being more likely to be diabetic. However, only $20 \%$ of the diabetics were aware of their conditions, and only $52 \%$ of those who know they are diabetic are under treatment. Unfortunately, for those receiving treatment, fewer than $4 \%$ are being effectively managed. ${ }^{45}$ Key reasons for low utilization of health care among the elderly include lack of money to pay for treatment and discrimination at the hands of health workers who tend to dismiss their ailments as "old age diseases." However, another big reason for the low level of access to health care to treat noncommunicable diseases is that the low-level health facilities that the poor typically access do not have any capacity to screen, diagnose, and treat cardiovascular and related non-communicable diseases. There is, therefore, an urgent need for policy and program shift to mainstream geriatrics in the healthcare systems and to consider instituting subsidies for healthcare for older people.

\section{CONCLUSION}

As urban slum settlements continue to grow in sub-Saharan Africa, the wellbeing of urban residents in general, and of the urban poor in particular, will 
increasingly shape national indicators on health, poverty, and other development issues. Constructive and sustainable urbanization could help propel Africa out of its perennial underdevelopment quagmire, as it has done in developed countries and the emerging middle-income countries around the globe. However, Africa's urban tipping point (which is set to take place in 2035 according to UN-Habitat's 2010 projections) would turn into a curse if the prevailing urbanization decay characterized by poor governance and planning, poor infrastructure and basic amenities, growing poverty, and deteriorating health outcomes are not compellingly and sustainably addressed. The UPHD program was designed to generate and provide the evidence base that would help policymakers, planners, development partners, and other stakeholders understand how the urban slum context affects health outcomes in order to stimulate policy and action for improving the well-being of slum residents. The program was situated in a uniquely rich longitudinal research environment setup in Korogocho and Viwandani slum settlements in Nairobi city. The research platform enabled the investigators to carry out comprehensive examination of the linkages between migration, poverty, and key health outcomes during childhood, adolescence, maternal adulthood, and old age.

This volume contains some of the first set of papers drawn from the UPHD program. The papers in this volume mostly use cross-sectional data from the first wave of data collected, and many of them do not adopt longitudinal analytical strategies because the project had not collected the full range of the longitudinal data when the papers were written. Nevertheless, the papers in this volume provide rich insights on the context in which slum dwellers live and how poverty and migration status interacts with health issues over the life course. Contrary to popular opinions and beliefs that see slums as homogeneous residential entities, the findings in this volume paint a picture of a highly dynamic and heterogeneous setting. For instance, the high levels of population mobility and poverty co-exist with a sizable well-settled population of people who are better off economically. The two slums from which the data were collected are remarkably different and so are villages even within the same slum in terms of poverty indicators. The relatively poor health outcomes that slum residents face at all stages of the life course are rooted in three key characteristics of slum settlements: poor environmental conditions and infrastructure, limited access to services due to lack of income to pay for treatment and preventive services, and reliance on poor quality and mostly informal and unregulated health services that are not well suited to meeting the unique realities and health needs of slum dwellers. As a result of a combination of these factors, slum residents exhibit relatively high levels of morbidity, low levels of access to reliable and affordable health care, and high levels of mortality. Evidently, policies and programs aimed at improving the well-being of slum dwellers should address comprehensively the underlying structural, economic, behavioral, and service-oriented barriers to good health and productive lives among slum residents. If this status quo is allowed to continue unabated, it is hard to see how Kenya and other African countries facing similar challenges can achieve their MDGs and graduate into middle-income countries as per their stated national plans and visions.

OPEN ACCESS This article is distributed under the terms of the Creative Commons Attribution Noncommercial License which permits any noncommercial use, distribution, and reproduction in any medium, provided the original author(s) and source are credited. 


\section{REFERENCES}

1. UN-Habitat. State of African cities 2010. Governance, Inequalities and Urban Land Markets. Nairobi, Kenya: UN-Habitat; 2010.

2. World urbanization prospects: the 2009 revision. http://esa.un.org/unpd/wup/index.htm. Published 2009. Accessed April 08, 2011.

3. Chen N, Valente P, Zlotnik H. What do we know about recent trends in urbanization? In: Bilsborrow RE, ed. Migration, Urbanization, and Development: New Directions and Issues. Norwell, MA: UNFPA-Kluwer Academic; 1998: 59-88.

4. Beguy D, Bocquier P, Zulu E. Circular migration patterns and determinants in Nairobi slum settlements. Demogr Res. 2010; 23(20): 549-586.

5. Department of Medical Health and Family Welfare. Five Year Urban Health Proposal (under RCH II) for Dehradun. Dehradun, India: Government of Uttaranchal; 2003.

6. Government of Kenya. Second Report on Poverty in Kenya-Incidence and Depth of Poverty. Nairobi: Central Bureau of Statistics, Ministry of Planning and National Development; 2000.

7. African Population and Health Research Center. Population and Health Dynamics in Nairobi's Informal Settlements: Report of the Nairobi Cross-sectional Slums Survey (NCSS) 2000. Nairobi, Kenya: African Population and Health Research Center; 2002.

8. UN-HABITAT. The state of African cities 2008 - a framework for addressing urban challenges in Africa. Nairobi: UN-HABITAT; 2008.

9. Population and Health Dynamics in Nairobi's Informal Settlements. Report of the Nairobi Cross-sectional Slums Survey (NCSS) 2000. Nairobi, Kenya: African Population and Health Research Center; 2002.

10. Taffa N, Chepngeno G, Amuyunzu-Nyamongo M. Child morbidity and healthcare utilization in the slums of Nairobi, Kenya. J Trop Pediatr. 2005; 51(5): 279-284.

11. Taffa N, Chepngeno G. Determinants of health care seeking for childhood illnesses in Nairobi slums. Trop Med Int Health. 2005; 10(3): 240-245.

12. Fotso JC, Ezeh A, Madise N, Ziraba A, Ogollah R. What does access to maternal care mean among the urban poor? Factors associated with use of appropriate maternal health services in the slum settlements of Nairobi, Kenya. Matern Child Health J. 2009; 13(1): 130-137.

13. Ziraba AK, Mills S, Madise N, Saliku T, Fotso JC. The state of emergency obstetric care services in Nairobi informal settlements and environs: results from a maternity health facility survey. BMC Health Serv Res. 2009; 9: 46.

14. Fotso JC, Ezeh A, Oronje R. Provision and use of maternal health services among urban poor women in Kenya: what do we know and what can we do? J Urban Health. 2008; 85 (3): 428-442.

15. Essendi H, Fotso, JC. Barriers to the utilization of formal emergency obstetric care services: accounts of slum dwellers in Nairobi, Kenya. J Urban Health. doi:10.1007/ s11524-010-9481-1.

16. Kyobutungi C, Ziraba AK, Ezeh A, Ye Y. The burden of disease profile of residents of Nairobi's slums: results from a Demographic Surveillance System. Popul Health Metr. 2008; 6: 1 .

17. Ziraba AK, Kyobutungi C, Zulu EM. Fatal injuries in the slums of Nairobi and their risk factors. J Urban Health. 2011. doi:10.1007/s11524-011-9580-7.

18. Ziraba AK, Madise N, Mills S, Kyobutungi C, Ezeh A. Maternal mortality in the informal settlements of Nairobi city: what do we know? Reprod Health. 2009; 6: 6.

19. Kabiru CW, Beguy D, Undie C-C, Zulu EM, Ezeh AC. Transition into first sex among adolescents in slum and non-slum communities in Nairobi, Kenya. J Youth Stud. 2010; 13 (4): 453-471.

20. Zulu EM, Dodoo FN-A, Ezeh AC. Sexual risk-taking in the slums of Nairobi, Kenya, 1993-98. Popul Stud. 2002; 56(3): 311-323. 
21. Beguy D, Kabiru CW, Nderu EN, Ngware MW. Inconsistencies in self-reporting of sexual activity among young people in Nairobi, Kenya. J Adolesc Health. 2009; 45(6): 595-601.

22. Fotso JC. Urban-rural differentials in child malnutrition: trends and socioeconomic correlates in sub-Saharan Africa. Health Place. 2007; 13(1): 205-223.

23. Madise NJ, Banda EM, Benaya KW. Infant mortality in Zambia: socioeconomic and demographic correlates. Biodemography Soc Biology. 2003; 50(1 \& 2): 148-166.

24. Madise NJ, Diamond ID. Determinants of infant mortality in Malawi: an analysis to control for death clustering within families. J Biosoc Sci. 1995; 27(1): 95-106.

25. Taffa N, Sundby J, Bjune G. Reproductive health perceptions, beliefs and sexual risk-taking among youth in Addis Ababa, Ethiopia. Patient Educ Couns. 2003; 49(2): 165-169.

26. Carael M, Ali M, Cleland J. Nuptuality and risk behaviour in Lusaka and Kampala. Afr J Reprod Health. 2001; 5(1): 83-89.

27. White R, Cleland J, Carael M. Links between premarital sexual behaviour and extramarital intercourse: a multi-site analysis. AIDS. 2000; 14(15): 2323-2331.

28. Zaba B, Pisani E, Slaymaker E, Boerma JT. Age at first sex: understanding recent trends in African demographic surveys. Sex Transm Infect. 2004; 80(Suppl II): ii28-ii35.

29. Brockerhoff M, Brennan E. The poverty of cities in developing regions. Popul Dev Rev. 1998; 24(1): 75-114.

30. World Bank. Entering the 21st century: World Development Report 1999/2000. New York, NY: World Bank; 2000.

31. Filmer D, Pritchett L. The effects of household wealth on educational attainment: evidence from 35 Countries. Popul Dev Rev. 1999; 25(1): 85-120.

32. Falkingham J. Measuring household welfare: problems and pitfalls with household surveys in central Asia. MOCT MOST Econ Policy Transitional Economies. 1999; 9(4): 379-393.

33. Montgomery M, Gragnolati M, Burke K, Paredes E. Measuring living standards with proxy variables. Demography. 2000; 37(2): 155-174.

34. Baker J, Schuler N. Analyzing urban poverty: a summary of methods and approaches. World Bank Policy Research Paper 2004 (3399); 2004.

35. Kyobutungi C, Ziraba A, Ezeh AC, Yé Y. The burden of disease profile of residents of Nairobi's slums: results from a demographic surveillance system. Popul Health Metr. 2008, 6: 1.

36. Bocquier P, Agwanda AO, Khasakhala A, Nyandega I, Owuor S, eds. Biography of three generations of Nairobi residents - Thirty years of social urban history. Dakar: Codesria; 2010.

37. Ziraba AK, Madise N, Mills S, Kyobutungi C, Ezeh A. Maternal mortality in the informal settlements of Nairobi city: what do we know? Reprod Health. 2009, 6: 6.

38. Cleland J, Bernstein S, Ezeh A, Faundes A, Glasier A, Innis J. Family planning: the unfinished agenda. Lancet. 2006; 368(9549): 1810-1827.

39. Batten L, Baschieri A, Zulu E. Female and male migration patterns into the urban slums of Nairobi, 1996-2006: evidence of feminisation of migration? XXVI IUSSP International Population Conference; October 2009; Marrakech, Morocco.

40. World Bank. Kenya poverty and inequality assessment. volume 1: synthesis report-draft report 2008. Washington, DC: 44190-KE.

41. Mutua M, Kimani-Murage E. Childhood vaccination in informal urban settlements in Nairobi, Kenya: who gets vaccinated? BMC Public Health. 2011; 11(1): 6.

42. Ndugwa RP, Zulu EM. Child morbidity and care-seeking in Nairobi slum settlements: the role of environmental and Socio-economic factors. J Child Health Care. 2008; 12(4): 314-328.

43. Ziraba AK, Mills S, Madise J, Saliku T, Fotso JC. The state of emergency obstetric care services in Nairobi informal settlements and environs. BMC Health Serv Res. 2009; 9: 46.

44. Chepngeno G, Ezeh A. Between a rock and a hard place: perception of older people living in Nairobi City on return migration to rural areas. Glob Ageing Issues Action. 2007; 4 (3): 67-78.

45. African Population and Health Research Center. Cardiovascular Diseases Risk Factors among the Urban Poor. APHRC Fact sheet. Nairobi, Kenya: African Population and Health Research Center; 2010. 